\title{
THE PSYCHOBIOLOGY OF PREMENSTRUAL DYSPHORIA: REVIEW OF THEORIES AND TREATMENTS
}

\author{
Meir Steiner and Bernard J. Carroll \\ Mental Health Research Institute, Department of Psychiatry, University of Michigan, \\ Ann Arbor, MI 48109, U.S.A.
}

(Received 15 December 1976)

\begin{abstract}
SUMMARY
(1) Premenstrual mood changes such as depression, elation, anxiety, hostility and irritability are a common cause of disability in women. (2) The nature of the disorder, the clinical dimensions, the incidence, the psychological and psychosocial theories are reviewed. (3) A long list of treatments recommended over the years is also reviewed and discussed, illustrating the ambiguity and uncertainty in this area. (4) The relationship to other periodic functional conditions, especially manic-depressive illness is discussed with particular emphasis on predictive studies. (5) The psychoneuroendocrine mechanisms possibly involved in these premenstrual conditions are reexamined. A specific role for prolactin in the etiology of these premenstrual dysphoric states is suggested.
\end{abstract}

\section{INTRODUCTION}

THE RUBRIC 'premenstrual tension syndrome' (PTS) encompasses a vast array of symptoms, involving many organs and systems. Over the years many theories about its etiology have been proposed and many kinds of treatment have been attempted. We do not propose to review the PTS literature exhaustively since a number of excellent reviews have appeared recently (Janowsky, Fann \& Davis, 1971; Cullberg, 1972; Tonks, 1975; Smith, 1975; Bardwick, 1976). The major issues can be stated in a concise way as follows:

(1) Although the incidence estimates vary widely, many women do indeed develop a variety of physical, psychological and behavioral changes in the late luteal phase of the menstrual cycle (Dalton, 1964).

(2) The clinical dimensions of this premenstrual syndrome have always been rather broad. Rees (1953) included the following symptoms: tension, irritability, anxiety, depressed mood, insomnia, fatigue, nausea or vomiting, headaches, dizziness, fluid retention, thirst, edema, breast enlargement and tenderness, pruritus, increased appetite and altered sexual drive. He also found an increased tendency for psychosomatic disorders such as asthma, migraine, rhinitis and angioneurotic edema to occur in the premenstruum. Dalton (1964) listed an equally wide range of symptoms and emphasized the major psychological symptoms of irritability, depression and lethargy.

(3) In a large factor analytic study of the PTS, Moos (1969b) identified eight major clusters of symptoms, and proposed that the undifferentiated term 'premenstrual syndrome' might more appropriately be labelled 'the premenstrual syndromes'. The symptom clusters which he identified were termed: pain, concentration, behavioral change, autonomic reactions, water retention, negative affect and arousal. An eighth cluster of 'control' 
symptoms was included to deal with the issue of nonspecific symptom-claiming. A number of distinct symptom profiles were identified.

(4) The dysphoria or negative affect which occurs premenstrually has been variously described as anxiety, hostility, irritability and depression. None of the studies to date have detailed the phenomenology of premenstrual affective change in a way which makes comparison with primary affective disorders possible. As Smith (1975) puts it: "The phenomenology of premenstrual depression has not been studied with the rigor necessary to fit it accurately into the current classification of depression".

(5) Premenstrual dysphoria can be distinguished from the condition of dysmenorrhoea (painful periods) (Coppen \& Kessel, 1963; Dalton, 1964; Moos, 1969a). The two conditions may occur together, but they are not associated strongly and they correlate differently with neuroticism. Similarly, premenstrual edema is a clinical entity which is sometimes but by no means always associated with premenstrual dysphoria (see Smith, 1975; Moos, 1969a).

(6) The incidence of significant premenstrual dysphoria is said to range from 25 to almost $100 \%$, depending upon the methods used to obtain the information and on the operational definition of the syndrome (Coppen \& Kessel, 1963; Brown-Parlee, 1973).

(7) Various psychological and psychosocial theories about the premenstrual syndromes have been advanced. It appears that these factors account for only a minor part of the variance in most studies. For example, Rees (1953) observed a correlation between premenstrual tension and neurotic predisposition, but noted that some very neurotic women had no symptoms of PTS, while others who improved psychologically with psychotherapy did not necessarily improve in their premenstrual tension. He concluded that physiological as well as psychological factors were important. Similar findings were published more recently by James \& Pollitt (1974).

(8) There are many reports dealing with the exacerbation of psychiatric illness during the premenstrual period. These are discussed by Smith (1975), Glass, Heninger, Lansky \& Talan (1971), Janowsky, Gorney, Castelnuovo-Tedesco \& Stone (1969) and Wetzel \& McClure (1972). Suicidal behavior, psychiatric hospitalization and psychiatric emergencies are all said to be increased above expected levels during the premenstruum. Premenstrual epilepsy is another well-known condition (Laidlaw, 1956; Dalton, 1964). Other reports of, miscellaneous behavior disorders in the premenstruum, such as hyperactive, aggressive violent or criminal behavior are less well substantiated (see Brown-Parlee, 1973; Smith, 1975).

(9) A number of authors have addressed the obvious possibility that episodic mood shifts which occur premenstrually might be related to manic-depressive illness. McClure, Reich \& Wetzel (1971) suggested such a connection after noting the existence of bipolar symptoms in some women with premenstrual mood change. In a later study from this group, young college women with premenstrual mood change were seen with increased frequency for affective disorders in the Student Health Service over the next 4 yr (Wetzel, Reich, McClure \& Wald, 1975). In this study, and in a related one from the St. Louis group (McClure et al., 1971) a small number of women was noted with premenstrual mood elevation; they were found to have personal and family histories of bipolar affective disorder. These reports tend to support the earlier claims of Kramp (1968) and of Williams \& Weekes (1952). By contrast, no increased prevalence of PTS was found by Coppen (1965) in patients 
with diagnosed affective disorders, whereas he did find a high incidence in neurotic patients. This study has been criticized by several later workers (Smith, 1975; Wetzel et al., 1975) for methodological reasons.

In a more recent study (Kashiwagi, McClure \& Wetzel, 1976) a definitely increased prevalence of premenstrual mood change was found in women with primary affective disorder, compared with women diagnosed as suffering from hysteria or anxiety neurosis. The discrepancy between these findings and the report of Coppen (1965) may be attributed to (1) sampling differences or (2) more likely, the diagnostic criteria employed.

Kashiwagi et al. (1976), following the model introduced by Feighner, Robins, Guze, Woodruff, Winokur \& Muzon (1972) for psychiatric diagnosis, adopted a new set of criteria for the diagnosis of premenstrual affective syndrome. The women in this study were originally referred to a neurologic clinic with functional headache, $75 \%$ were black and the criteria used included a mixture of physical and psychological symptoms. Diamond, Rubinstein, Dunner \& Fieve (1976) compared women with previously diagnosed affective illness to a control group and found no difference with regard to somatic symptoms at menstruation. Dysphoric symptoms in relation to the menstrual cycle showed only a slight trend toward increased reporting by the affective group. There was a tendency observed for women to be hospitalized for depression during the late premenstrual phase of the cycle. Their interpretation of these findings is that women predisposed to affective disorders, but not suffering from a current episode, experience menstruation in much the same way that normal women do. On the other hand, patients in the middle of an episode may experience a premenstrual worsening of their current symptoms, so that hospital admission is often precipitated at that time.

(10) The scientific status of much of the clinical lore associated with the concept of premenstrual tension has been subjected to searching critiques by Brown-Parlee (1973) and Smith (1975). Notwithstanding these reservations, the existence of the syndrome (or syndromes) is not doubted seriously, and it does appear to be a significant cause of distress for many women and their families. The description by Dalton (1971) is an arresting one: "In premenstrual depression the mood changes are short-lived, the depression lasting only a few days at a time with improvement, often abrupt, occurring during menstruation. But the depth of depression may be extreme, reaching suicide level, or a temporary psychosis may develop. The depression is accompanied by tension, irritability with aggression which may result in a battered baby or bruised husband, and lethargy, both mental and physical."

\section{BIOLOGICAL THEORIES OF PREMENSTRUAL DYSPHORIA}

\section{Hormonal changes during the normal menstrual cycle}

The interactions of the hypothalamus, pituitary gland, ovary and adrenal cortex, together with the endometrium, are responsible for the cyclical regular and recurrent process of ovulation and menstruation. In response to a hypothalamic releasing factor, the anterior pituitary produces follicle-stimulating hormone (FSH) which stimulates the development of the ovarian follicles and causes constant estrogen secretion during this phase of the cycle. Estrogen secretion rises to a peak at mid cycle when, through a hypothalamic feedback mechanism, a surge of luteinizing hormone (LH) occurs together with a peak of FSH 

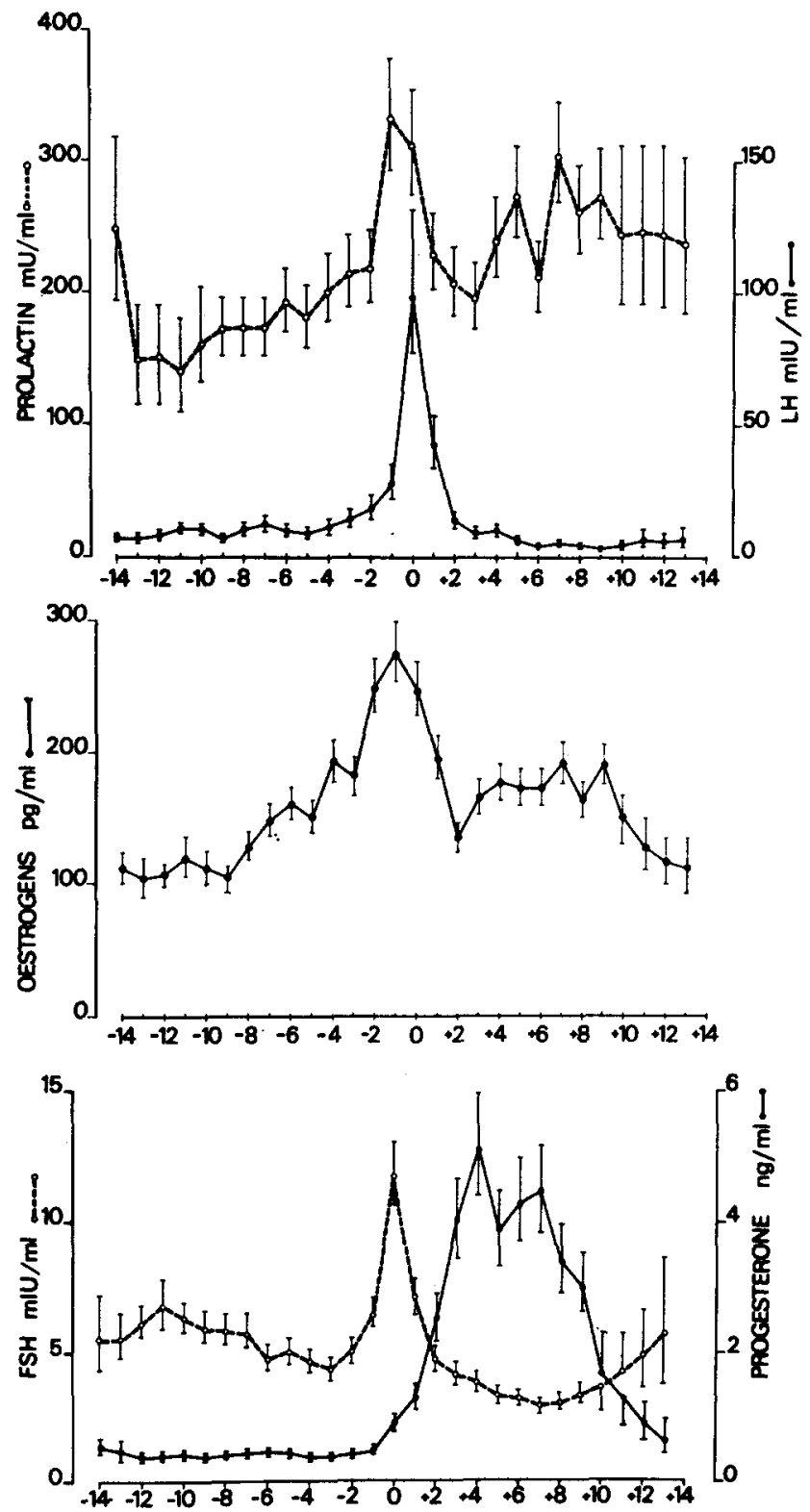

FIG. 1. Mean serum prolactin, LH, estrogens, FSH and progesterone in 10 women with regular menstrual cycles, sampled between late morning and early afternoon. From Robyn et al. (1973) Reproduced by permission of Excerpta Medica Amsterdam, American Elsevier Publishing Company, Inc., New York. 
release. Ovulation then occurs and the corpus luteum begins to secrete progesterone. This is termed the luteal phase of the cycle. If fertilization of the ovary has not occurred, then progesterone secretion begins to decrease about 6 days prior to menstruation. Estrogen secretion from the ovary also begins to fall at about the same time (Fig. 1).

Prolactin. There has been considerable disagreement about the cyclic secretion of prolactin during the normal cycle. Robyn, Delvoye, Nokin, Vekemans, Badawi, Perez-Lopez \& L'Hermite (1973) have reported that prolactin secretion rises to a mid-cycle peak together with plasma estrogen levels, drops temporarily after ovulation, and then increases again so that levels during the luteal phase are considerably higher than during the follicular phase. Figure 1 displays the monthly cycle of prolactin, $\mathrm{LH}$, estrogens, FSH and progesterone during the normal cycle. According to Robyn, plasma prolactin levels remain elevated during the late luteal phase at a time when estrogen and progesterone levels are dropping rapidly. Prolactin levels do not return to follicular phase levels until after the onset of menstruation (Fig. 1). Several years ago other workers (e.g. McNeilly, Evans \& Chard, 1973) were in disagreement with this report from Robyn's group and maintained that plasma prolactin levels showed essentially no cyclic change through the events of ovulation and menstruation. More recently, McNeilly \& Chard (1974) have published further detailed data which indicate that there is, in fact, a great deal of variability from one woman to another regarding the menstrual pattern of prolactin secretion. In some individual women there appears to be little change throughout the cycle while other women have been identified clearly by McNeilly and Chard to have the mid cycle peak and luteal phase elevations which were published by Robyn et al. (1973). All workers seem to agree that the variability which is found in plasma prolactin levels during the luteal phase is much greater than during the follicular phase.

All of these studies are reported on prolactin levels obtained during the morning hours. The circadian rhythm of plasma prolactin is well known and the highest levels occur during the late hours of sleep (around 5 a.m.) (Frantz, Habif, Hyman, Suh, Sassin, Zimmerman, Noel \& Kleinberg, 1973). A more clear picture of the menstrual changes in prolactin secretion might well be obtained by sampling during the night. For example, Robyn et al. (1973) demonstrated that the mean serum prolactin levels in men and women are almost identical at 9 a.m. and at 1 p.m. whereas large differences can be detected, with women having higher values, at 1 a.m. and 5 a.m. To summarize: in at least some women the plasma prolactin levels which occur during the luteal phase of the cycle are considerably higher than during the follicular phase and these high levels are maintained until the onset of menstruation, at a time when estrogen and progesterone values are dropping rapidly.

$A C T H$ and cortisol. Both ACTH and cortisol levels tend to show a cyclic pattern, with relatively lower levels during the follicular than during the luteal phase. Both hormones show a modest increase at the time of ovulation and a small decrease during the premenstrual phase (Genazzani, Lemarchand-Beraud, Aubert \& Felber, 1975). Once again, however, these data are taken from single samples obtained in the morning and they do not give any reflection of possible alterations in the circadian secretory pattern.

Mineralocorticoids. The urinary excretion of aldosterone during the luteal phase is about twice that of the follicular phase (Reich, 1962) and this increase is known to be accompanied by similar changes in the secretion rate of aldosterone (Gray, Strausfeld, Wantanabe, 
Sims \& Solomon, 1968). The daily pattern of plasma aldosterone concentrations was studied by Katz \& Romfh (1972) who demonstrated that the fasting supine plasma aldosterone levels in normally menstruating women rose to a peak at about the ninth or tenth day before menstruation and then dropped rapidly on about the sixth or seventh day before menstrual bleeding began. Similar results were reported by Michelakis, Yoshida \& Dormois (1975). These authors demonstrated also that there were no changes in plasma aldosterone levels detected during anovulatory cycles. Schwartz \& Abraham (1975) have confirmed that the morning plasma aldosterone levels during the follicular phase are considerably lower than during the luteal phase in menstruating women. They demonstrated as well that plasma corticosterone levels follow a similar pattern. Two patients with menstrual edema had particularly high levels of aldosterone and corticosterone. Dexamethasone treatment produced at least partial suppression of corticosterone levels in all subjects and suppressed also the elevated aldosterone levels in the two women with edema. However, the aldosterone levels of normal women were not suppressed by dexamethasone. The same group has also shown that plasma levels of desoxycorticosterone are significantly higher in the luteal than in the follicular phase of the menstrual cycle (Manlimos, Maroulis \& Abraham, 1975).

Renin-angiotensin system. As mentioned above, Schwartz \& Abraham (1975) showed that the elevated luteal levels of plasma aldosterone in normal women were not suppressible by dexamethasone. In most women during the luteal phase, aldosterone secretion is believed to rise as a result of increased activity in the renin-angiotensin system. Sundsfjord \& Aakvaag (1970) showed that plasma angiotensin II levels during the luteal phase were almost double those during the follicular phase, and they suggested that the sequence of events occurring was: increased progesterone secretion leading to sodium loss through the kidneys, leading in turn to increased secretion of renin and angiotensin. The angiotensin in turn would lead to increased secretion of aldosterone. Subsequently Katz \& Romfh (1972) demonstrated that plasma renin activity rises in the luteal phase immediately before plasma aldosterone levels and that plasma renin activity then falls, with the aldosterone levels decreasing shortly afterwards in the late luteal phase (Fig. 2). Michelakis et al. (1975) obtained the same results as Katz \& Romfh (1972) and they further demonstrated that during anovulatory cycles, when progesterone secretion and pregnanediol excretion did not rise during the

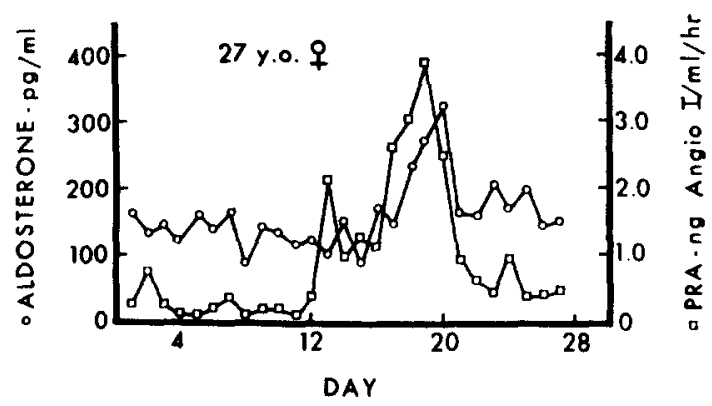

FIG. 2. Plasma aldosterone and plasma renin activity (PRA) in one woman during a normal cycle. From Katz \& Romfh (1972). Reproduced by permission of the Editor, Journal of Clinical Endocrinology and Metabolism. 
luteal phase, then no changes occurred in plasma aldosterone levels or plasma renin activity. A similar finding for anovulatory cycles was reported by Sundsfjord \& Aakvaag (1970). Besides this indirect action of progesterone in causing increased renin secretion, estrogens interact with the system by inducing the hepatic formation of renin substrate (angiotensinogen) (Laragh, 1974).

Androgens. The plasma levels of testosterone and androstenedione generally show a mid-cycle peak (Judd \& Yen, 1973) (Fig. 3). This was confirmed also by Abraham who showed in addition that the ovary as well as the adrenal contributes to peripheral levels of

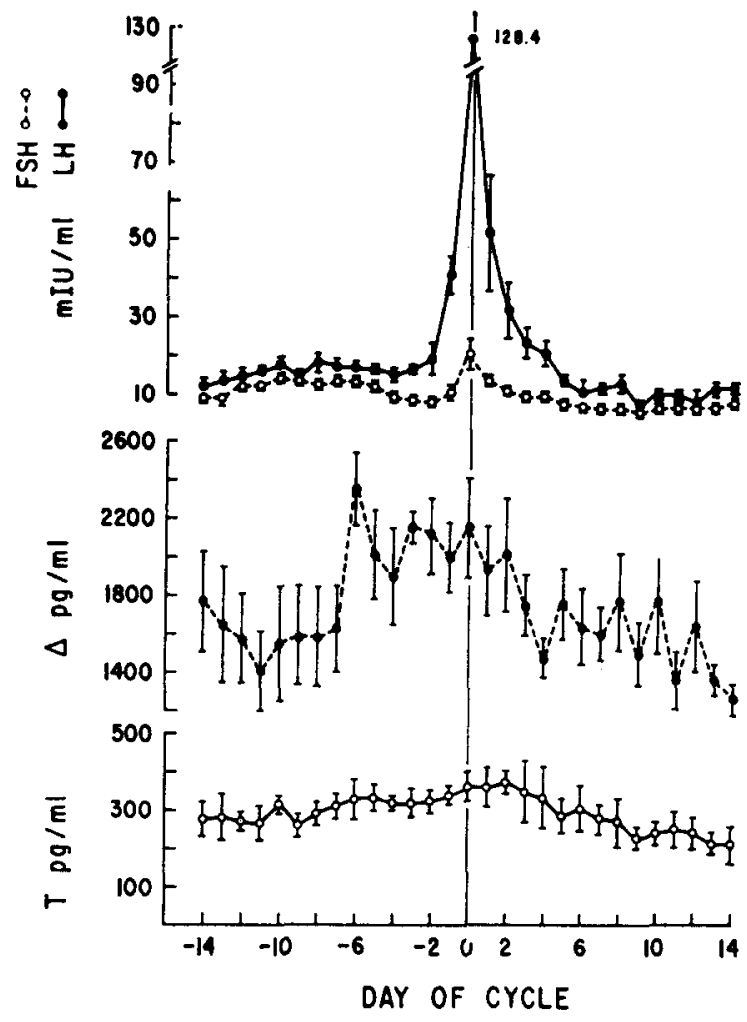

Fig. 3. Mean values of LH, FSH, androstenedione and testosterone in 6 women during normal menstrual cycles. From Judd \& Yen (1973). Reproduced by permission of the Editor, Journal of Clinical Endocrinology and Metabolism.

testosterone, dihydrotestosterone and androstenedione (Abraham \& Chakmakjian, 1973; Abraham, 1974). Plasma androgen levels do not appear to have been studied in women with premenstrual dysphoria. This lack is rather surprising in view of the suggested association between testosterone and both sexual drive and aggression (Rose, 1972) and also in view of the common exacerbation of acne which occurs with premenstrual dysphoria (Sutherland \& Stewart, 1965). The mid-cycle peak of circulating androgens corresponds in 
time with the peak in estrogens and prolactin. It was recently shown that both the nocturnal and diurnal secretion of testosterone in males is influenced by concurrent secretion of prolactin (Rubin, Gouin, Lubin, Poland \& Pirke, 1975; Rubin, Poland \& Tower, 1976). It would be of interest to document the cyclic changes in testosterone levels in women who also experience a luteal elevation of prolactin.

In summary, phasic changes in the secretion of gonadatropins, prolactin, progesterone, estrogens, androgens and mineralocorticoids are known to occur during the menstrual cycle. Changes in the renin-angiotensin system appear to precede alterations in aldosterone secretion and to be determined by the secretion of progesterone from a functioning corpus luteum. During the late luteal phase of the cycle the levels of renin, angiotensin, progesterone, estrogen and androgens drop sharply beginning about 6 days before menstruation. In at least some women the levels of prolactin remain elevated and do not drop until the onset of menstruation.

\section{Estrogen-progesterone imbalance theories}

Most early investigators of premenstrual tension focused naturally enough on the relationship between the ovarian hormones and behavioral syndromes. Smith (1975) has reviewed these theories. At one time or another, workers have suggested that the behavioral changes were caused by (a) a relative deficiency of estrogens; (b) a relative deficiency of progesterone; (c) idiosyncratic sensitivity to estrogens or (d) a withdrawal reaction to either estrogen or progesterone. No general agreement about these hormone changes has been reached and this is reflected by the very large number of suggested treatments. Dalton $(1964,1971)$ has been an enthusiastic advocate of the progesterone deficiency theory and has actively promoted the use of progesterone in the treatment of the condition. The premenstrual syndrome was attributed to 'progesterone withdrawal'; other reports appear to support the 'estrogen withdrawal' theory. Laboratory evidence for both these patterns has been reported (see Smith, 1975). The confusion and disagreement between these two schools may result from variations in the definitions used by different investigators. Dalton $(1964,1971)$ appears to be describing mostly a syndrome of premenstrual irritability and hostility, rather than depression as such. Backstrom \& Carstensen (1974) presented impressive evidence for low progesterone levels in women with 'premenstrual anxiety'. Cullberg (1972) also concluded that some cases of 'premenstrual irritability' were due to estrogen dominance (i.e. a relative lack of progesterone). On the other hand, Smith and his associates, who carefully selected a group of women with 'premenstrual depression, as opposed to irritability, edema or anxiety' found minimal differences in plasma progesterone levels, and no improvement with progesterone injections (Smith, 1975). From reviewing these reports it seems possible that premenstrual irritability-anxiety-hostility may be a separate condition from premenstrual depression as such. These two conditions could also coexist in some women.

\section{Pyridoxine (vitamin B6) deficiency}

A number of workers have speculated that the depressed affect which sometimes accompanies oral contraceptive treatment might be related to a functional deficiency of pyridoxine, and that a similar problem could be the basis for premenstrual dysphoria (Rose, 1969; 
Winston, 1973; Herzberg, Draper, Johnson \& Nicol, 1971). The successful use of pyridoxine to treat premenstrual tension was reported by Winston (1969) and by Baumblatt \& Winston (1970) but could not be confirmed in a better controlled study by Stokes $\&$ Mendels (1972).

\section{Renin-angiotensin-aldosterone system}

Janowsky, Berens \& Davis (1973) suggested that premenstrual depression might be related to activation of the renin-angiotensin-aldosterone system. They studied young college women on a metabolic ward and documented changes in 'negative affect', urinary sodium and potassium excretion, and body weight. They observed rising levels of negative affect until the day of menstruation when the affect scores and body weight dropped dramatically. The urinary potassium/sodium ratios increased until 4 days before menstruation, at which time they dropped sharply. On the basis of their data, Janowsky et al. (1973) suggested that the negative affect was more closely related in time to electrolyte and water retention than to changes in estrogen and progesterone. They suggested that direct actions of angiotensin on the nervous system might cause the negative affect. Once again some aspects of the diagnostic criteria used in this study are questioned. In this study 'negative affect' included depression together with symptoms such as irritability, jitteriness, tension and argumentativeness, which may not all belong to the same category. As already mentioned, more recent studies have shown clearly that the activity in the renin-angiotensinaldosterone system in fact drops sharply about 6 days before menstruation occurs. In light of this new information it seems unlikely that angiotensin was related to the late luteal 'negative affect' and fluid retention, which persisted up until the day of menstruation.

Adamopoulos, Loraine, Lunn, Coppen \& Daly (1972) have demonstrated that premenstrual depression and dysphoria do occur in menstrual cycles which are anovulatory. Since changes in the renin-angiotensin-aldosterone system do not occur in such cycles (see above) it is unlikely that angiotensin is responsible for the behavioral changes seen at this time, as had been suggested by Janowsky et al. (1973). These findings with anovulatory cycles also tend to rule out progesterone as the major factor in producing premenstrual dysphoria.

\section{Monoamine oxidase activity}

High levels of plasma monoamine oxidase (MAO) activity have been demonstrated in premenstrual women (Klaiber, Kobayaski, Broverman \& Hall, 1971). These changes in plasma MAO activity are paralleled by a premenstrual rise in the enzyme activity in the endometrium during the late luteal phase (Grant \& Pryse-Davies, 1968). These workers also noted that oral contraceptives with a high progestogen content induce major elevations in endometrial MAO activity, whereas the more estrogenic compounds do not. Belmaker, Murphy, Wyatt \& Loriaux (1974) have demonstrated a peak platelet MAO activity during the mid-cycle phase and a nadir premenstrually. There were no significant relationships between platelet MAO activity and a global scale of menstrual mood variations. These results confirm a previous study by Gilmore, Robinson, Nies, Sylvester \& Ravaris (1971), Low platelet MAO levels were also reported in premenstrual monkeys (Redmond, Murphy, Baulu, Ziegler \& Lake, 1975). Both Klaiber and Grant have speculated that the progesto- 
genic stimulation causes generalized changes in MAO activity which could be a factor in the occurrence of depression and loss of libido in susceptible women. As yet however, there is no direct evidence that these peripheral changes in MAO activity during the cycle occur in the human central nervous system.

\section{REVIEW OF TREATMENTS}

The long list of treatments recommended over the years for the premenstrual syndromes illustrates all too clearly the ambiguity and uncertainty in this area. Oral contraceptives, synthetic progestogens, progesterone itself, aldosterone antagonists, diuretics, minor tranquillizers, lithium, vitamins, psychotherapy and also physical therapy have been advocated at one time or another. The outstanding feature of the therapeutic literature in premenstrual dysphoria is that all of these treatments have been introduced with enthusiasm on the basis of uncontrolled studies but none has survived rigorous testing in controlled clinical trials. At the time of writing there is no single treatment which is universally accepted as effective. We noted above that much of the difficulty in this area probably results from the fact that at least two different subgroups may be included under the general heading 'premenstrual tension syndrome'.

\section{Controlled studies}

Cullberg (1972) examined 320 women and claims to have identified a small subgroup of patients with premenstrual dysphoria who "were clearly hormone-dependent". Oral contraceptives which were highly estrogenic made them worse whereas strongly progestogenic oral contraceptives improved their symptoms. The precise behavioral characteristics of this subgroup were not specified clearly. There is a large and somewhat confusing literature on the effects of oral contraceptives. Moos (1969a) and also Herzberg et al. (1971) found that in general premenstrual symptoms were decreased in women on oral contraceptives. Nevertheless, there did appear to be a small group who were made worse. Coppen, Milne, Outram \& Weber (1969) and Jordheim (1972) compared synthetic progestogens to diuretics, placebo and a progestogen-diuretic combination. The results of these double-blind studies failed to confirm the effectiveness of any of the active agents.

Dalton $(1964,1971)$ has been an enthusiastic advocate for the use of intramuscular progesterone. Both she and Rees (1953) report that some women improved dramatically with progesterone treatments. However, there are no carefully controlled studies from these authors to support their claims. In one well-controlled study by Smith (1975) progesterone was shown to have no effect in women carefully selected for premenstrual depression without irritability and hostility. In the same study the aldosterone antagonist, spironolactone, was used in another group. The results indicated that there were no cases in which this drug was either effective or deleterious. Diuretic agents are at best only adjunctive treatments and have not been proven effective in controlled studies (see Smith, 1975). The claims for pyridoxine were reviewed briefly in an earlier section.

\section{Lithium}

Given the cyclic nature of the syndrome and the prominence of affective symptoms, it is surprising that so little has been reported on the effects of lithium on premenstrual dysphoria. 
Sletten \& Gershon (1966) gave $300 \mathrm{mg}$ of lithium carbonate 3 times daily beginning 10 days before the expected onset of menstruation and ending with the menstrual flow. Eight women with a history of irritability, headaches, explosive emotional outbursts, tension, insomnia and depression during the premenstrual period were said to be treated successfully with this regimen for up to $12-18$ months. This was an open, uncontrolled study. Fries (1969) mentioned that lithium had a good effect in 2 out of 5 women who were treated for premenstrual tension. He did not specify the symptomatology or the dosage and administration schedule of lithium, stating only that they were treated for more than one menstrual cycle. Tupin (1972) mentions one case with premenstrual tension who improved partly with lithium therapy. The detailed data were not given. Singer, Cheng \& Schou (1974) compared lithium with placebo in a double-blind, multiple random cross-over study involving 19 outpatients suffering from premenstrual tension. Lithium treatment was given throughout the month. The patients had good improvements with both lithium and placebo and there were no differences between the two treatments. It is difficult to evaluate the significance of this study in view of the fact that 12 of their patients were diagnosed as having concomitant other psychiatric conditions ( 3 affective psychoses, 4 neuroses and 5 remitted schizophrenics). Mattsson \& Von Schoultz (1974), using a cross-over double blind design, conducted a well controlled study of lithium treatment. Eighteen women received lithium carbonate, $200 \mathrm{mg} 4$ times daily beginning 14 days before the first day of expected menstrual flow. The lithium treatment was compared with 2 other regimens-a diuretic (chlorthalidone), and placebo. Each treatment was given over 2 premenstrual periods. Each treatment improved the symptoms of premenstrual tension. The rank order of effectiveness was placebo first, followed by the diuretic, with lithium least active. A diuretic effect of the lithium accompanied improvement in some cases. Once again, in this study, the symptoms described involved at least 4 subgroups, i.e. anxiety-tension, depression, irritability and feelings of swelling. Horrobin, Manku, Nassar, \& Evered (1973) reported on one woman with a severe premenstrual edema syndrome. She was given $500 \mathrm{mg}$ lithium carbonate daily beginning on the day of elevation of basal body temperature and continuing until menstruation occurred. She was reported to be free of edema for 2 complete cycles. This patient also experienced severe dysphoria coincident with the premenstrual edema, and her psychological symptoms were likewise relieved during her treatment with lithium. After 6 months, however, the physical and psychological effectiveness of this treament was greatly diminished (Horrobin, Mtabaji, Karmali, Manku \& Nassar, 1976).

On the basis of these studies carried out to date, the possible effectiveness of lithium in any subgroup with the premenstrual syndrome remains still an open question.

\section{Bromocriptine}

A very promising new form of treatment for premenstrual symptoms was reported recently by Benedek-Jaszmann \& Hearn-Sturtevant (1976). They treated a large number of women with bromocriptine (2-bromo-a-ergocryptine, CB 154, Sandoz), which is a drug that suppresses the secretion of prolactin from the anterior pituitary. In both open and double-blind evaluations this drug produced dramatic relief of several types of premenstrual symptoms-breast symptoms, edema, weight gain and mood. The frequency and quality of virtually complete improvement obtained with bromocriptine were remarkable by com- 
parison with the other treatments reviewed earlier. Cole, Evered, Horrobin, Manku, Mtabaji \& Nassar (1975) have obtained similar results in one woman over a period of $2 \mathrm{yr}$. In fact, this is the same woman mentioned previously (Horrobin et al., 1973, 1976) who was treated initially with lithium and then switched to bromocriptine.

Bromocriptine has been shown to be a specific anti-galactic agent in animal studies (Billetier \& Fluckiger, 1971), in puerperal women (Varga, Lutterbeck, Pryor, Wenner \& Erb, 1972), in women with galactorrhea and menstrual disturbances (Rolland, Schellekens \& Lequin, 1974) and in men with galactorrhea and impotence (Besser, Parke \& Edwards, 1972). Recently Rolland and co-workers (Rolland, Lequin, Schellekens \& DeJong, 1975a; Rolland, DeJong, Schellekens \& Lequin, 1975b) have also shown that bromocriptine administration during the puerperal period inhibits prolactin secretion and causes an immediate restoration of normal ovulatory function with the appearance of regular periods. High levels of prolactin are believed to inhibit ovulation (Seppala, Hirvonen, Ranta, Virkkunen \& Leppaluoto, 1975) and this may account for the fact that many of the patients studied by Benedek-Jaszmann \& Hearn-Sturtevant (1976) became pregnant while their prolactin secretion was inhibited by bromocriptine. If high prolactin levels are involved in the etiology of the premenstrual tension syndrome this would also help to explain the high incidence of anovulatory cycles noted in such women by Adamopoulos et al. (1972).

\section{COMMENT}

The pleomorphic nature of premenstrual physiologic and psychologic symptoms has defied a convincing psychobiologic explanation. Even the formal nosology of the behavioral changes is disputed; recent studies have been cited which either support or reject the idea that premenstrual depression is related to the primary affective disorders. Although the present reviewers are inclined to agree with Diamond et al. (1976) that there is no such specific association, it is still the case that "the phenomenology of premenstrual depression has not been studied with the rigor necessary to fit it into the current classification of depression" (Smith, 1975). Some of the studies we have reviewed suggest that there are several distinct premenstrual behavioral syndromes-depression, elation and hostile irritability. While it may be possible to identify subgroups of women with these circumscribed premenstrual syndromes, it nevertheless seems that most women experience some combination of these symptoms. Some of the psychoendocrine studies we have discussed above suggest that premenstrual irritability may be related to low progesterone levels; this factor appears to be less important in the case of premenstrual depression. The more recent proposal that premenstrual 'negative affect' is determined by the renin-angiotensinaldosterone system has not been supported by subsequent detailed studies of this system during the menstrual cycle. Various other biological theories of the premenstrual syndrome have been suggested, but without convincing evidence.

This underlying difficulty in our clinical and endocrinologic understanding of the premenstrual syndrome is reflected in the number of suggested treatments: oral contraceptives, synthetic progestogens, progesterone, aldosterone antagonists, diuretics, vitamins, minor tranquillizers, lithium, psychotherapy and physical therapy. Controlled studies have repeatedly failed to confirm the effectiveness of any of these treatments. The possible 
utility of lithium has not yet been conclusively ruled out, although the available evidence is not encouraging.

By contrast with these previous treatments, the recent trials of bromocriptine are much more promising. This drug is believed to act by suppressing prolactin secretion and appears to be effective against both physical and behavioral premenstrual symptoms. If these initial reports are confirmed in subsequent studies, theories about the psychobiology of pre-menstrual dysphoria will need to be revised to take into account the role of prolactin.

\section{REFERENCES}

Abraham, G. E. (1974) Ovarian and adrenal contribution to peripheral androgens during the menstrual cycle. J. clin. Endocr. Metab. 39, 340-346.

Abraham, G. E. \& Chakmakjan, Z. H. (1973) Serum steroid levels during the menstrual cycle in a bilaterally adrenalectomized woman. J. clin. Endocr. Metab. 37, 581-587.

Adamopoulos, D. A., Loraine, J. A., Lunn, S. F., Coppen, A. H. \& Daly, R. J. (1972) Endocrine profiles in premenstrual tension. Clin. Endocr. 1, 283-292.

BACKSTrom, T. \& CARSTENSEN, H. (1974) Estrogen and progesterone in plasma in relation to premenstrual tension. J. Steroid Biochem. 5, 257-260.

BARDwick, J. M. (1976) Psychological correlates of the menstrual cycle and oral contraceptive medication. In Hormones, Behavior and Psychopathology, E. J. Sachar (Ed.), pp. 95-103. Raven Press, New York.

Baumblatt, M. J. \& Winston, F. (1970) Pyridoxine and the pill. Lancet i, 833.

Belmaker, R. H., Murphy, D. L., Wyatt, R. J. \& Loriaux, D. L. (1974) Human platelet monoamine oxidase changes during the menstrual cycle. Archs gen. Psychiat. 31, 553-556.

Benedek-Jaszmann, L. J. \& Hearn-Sturtevant, M. D. (1976) Premenstrual tension and functional infertility. Lancet i, 1095-1098.

Besser, G. M., Parke, L. \& Edwards, C. R. (1972) Galactorrheoa: successful treatment with reduction in plasma prolactin levels by bromergocryptine. Br. med. J. iii, 669-672.

Billetier, E. \& Fluckiger, E. (1971) Evidence for a luteolytic function in the intact cyclic rat using 2-Br- $\alpha$ ergocryptine (CB-154). Experientia, Basel 27, 464.

Brown-Parlee, M. (1973) The premenstrual syndrome. Psychol. Bull. 80, 454-465.

Cole, E. N., Evered, D., Horrobin, D. F., Manku, M. S., Mtabaji, J. P. \& Nassar, B. A. (1975) Is prolactin a fluid and electrolyte regulating hormone in man? J. Physiol. 252, 54-55.

COPPEN, A. (1965) The prevalence of menstrual disorders in psychiatric patients. Br. J. Psychiat. 111, 155167.

Coppen, A. \& Kessel, N. (1963) Menstruation and personality. Br. J. Psychiat. 109, 711-721.

Coppen, A. J., Milne, H. B., Outram, D. H. \& Weber, J. C. P. (1969) Dytide, norethisterone and a placebo in the premenstrual syndrome-a double-blind comparison. Clin. Trials J. 6, 33-36.

CullberG, J. (1972) Mood changes and menstrual symptoms with different gestagen/estrogen combinations. Acta psychiat. scand. Suppl. 236, 1-84.

Dalton, K. (1964) The Premenstrual Syndrome. Heinemann Medical, London.

Dalton, K. (1971) Prospective study into puerperal depression. Br. J. Psychiat. 118, 689-692.

Diamond, S. B., Rubinstein, A. A., Dunner, D. L. \& Fieve, R. R. (1976) Menstrual problems in women with primary affective illness. Compreh. Psychiat. 17, 541-548.

Feighner, J. P., Robins, E., Guze, S. B., WoOdruff, R. A., Winokur, G., \& Muzon, R. (1972) Diagnostic criteria for use in psychiatric research. Archs. gen. Psychiat. 26, 57-63.

Frantz, A. G., Habif, D. V., Hyman, G. A., Suh, H. K., Sassin, J. F., Zimmerman, E. A., Noel, G. L. \& KLeINBerg, D. L. (1973) Physiological and pharmacological factors affecting prolactin secretion, including its suppression by L-DOPA in the treatment of breast cancer. In Human Prolactin, J. L. Pasteels and C. Robyn (Eds.), pp. 273-290. Excepta Medica, Amsterdam.

FrIEs, H. (1969) Experience with lithium carbonate treatment at a psychiatric department in the period 1964-1967. Acta psychiat. scand. Suppl. 207, 41-43.

Genazzani, A. R., Lemarchand-Beraud, T,, Aubert, M. L. \& Felber, J. P. (1975) Pattern of plasma ACTH, hGH, and cortisol during menstrual cycle. J. clin. Endocr. Metab. 41, 431-437.

Gllmore, N. J., Robinson, D. S., Nies, A., Sylvester, D. \& Ravaris, C. L. (1971) Blood monoamine oxidase levels in pregnancy and during the menstrual cycle. J. psychosom. Res. 15, 215-220. 
Glass, G. S., Heninger, G. R., Lansky, M. \& Talan, K. (1971) Psychiatric emergency related to the menstrual cycle. Am. J. Psychiat. 128, 705-711.

Grant, E. C. G. \& PRYSE-Davies, J. (1968) Effects of oral contraceptives on depressive mood changes and on endometrial monoamine oxidase and phosphatases. Br. med. J. iii, 777-780.

Gray, M. J., Strausfeld, K. S., Wantanabe, M., Sims, E. A. H. \& Solomon, S. (1968) Aldosterone secretory rates in the normal menstrual cycle. J. clin. Endocr. Metab. 28, 1269-1275.

Herzberg, B. N., Draper, K. C., Johnson, A. L. \& Nicol, G. C. (1971) Oral contraceptives, depression. and libido. Br. med. J. iii, 495-500.

Horrobin, D. F., Manku, M. S., NAssar, B. \& Evered, D. (1973) Prolactin and fluid and electrolyte balance In Human Prolactin, J. L. Pasteels, C. Robyn (Eds.), pp. 152-155. Excerpta Medica, Amsterdam.

horrobin, D. F., Mtabaj, J. P., Karmali, R. A., MankU, M. S. \& Nassar, B. A. (1976) Prolactin and mental illness. Post-grad. med. J. 52 (Suppl. 3), 79-85.

James, H. \& Pollitt, J. (1974) Personality and premenstrual tension. $R$. Soc. Med. Proc. 67, 921-923.

JANOWSKY, D. S., FANN, W. E. \& DAVIS, J. M. (1971) Monoamines and ovarian hormone-linked sexual and emotional changes: a review. Archs sex. Behav. 1, 205-218.

JANOwsky, D. S., Berens, S. C. \& Davis, J. M. (1973) Correlations between mood, weight, and electrolytes during the menstrual cycle: a renin-angiotensin-aldosterone hypothesis of premenstrual tension. Psychosom. Med. 35, 143-154.

Janowsky, D. S., Gorney, R., Castelnuovo-Tedesco, P. \& Stone, C. B. (1969) Premenstrual-menstrual increases in psychiatric hospital admission rates. Am. J. Obstet. Gynec. 103, 189-191.

JoRDHEIM, O. (1972) The premenstrual syndrome-clinical trials of treatment with a progestogen combined with a diuretic compared with both a progestogen alone and with a placebo. Acta obstet. gynec. scand. $51,77-80$.

JUDD, H. L. \& YEN, S. S. C. (1973) Serum androstenedione and testosterone levels during the menstrual cycle. J. clin. Endocr. Metab. 36, 475-481.

Kashiwagi, T., McClure, J. N., JR. \& Wetzel, R. D. (1976) Premenstrual affective syndrome and psychiatric disorder. Dis. nerv. Syst. 37, 116-119.

KATZ, F. H. \& ROMFH, P. (1972) Plasma aldosterone and renin activity during the menstrual cycle. J. clin. Endocr. Metab. 34, 819-821.

Klaiber, E. L., Kobayashi, Y., Broverman, D. M. \& Hall, F. (1971) Plasma Monoamine Oxidase activity in regularly menstruating women and in amenorrheic women receiving cyclic treatment with estrogens and a progestin. J. clin. Endocr. Metab. 33, 630-637.

Kramp, J. L. (1968) Studies on the premenstrual syndrome in relation to psychiatry. Acta psychiat. scand. Suppl. 203, 261-267.

LAIDLAW, J. (1956) Catamenial epilepsy. Lancet ii, 1235-1237.

LARAGH, J. H. (1974) Oral contraceptives, female hormones, the renin axis and high blood pressure. In Oral Contraceptives and High Blood Pressure, M. J. Fregly and M. S. Fregly (Eds.), pp. 50-67. Dolphin Press, Gainesville, Fla.

MCClure, J. N., JR., Reich, T. \& Wetzel, R. D. (1971) Premenstrual symptoms as an indicator of bipolar affective disorder. Br.J.Psychiat. 119, 527-528.

MCNeilly, A. S. \& ChaRd, T. (1974) Circulating levels of prolactin during the menstrual cycle. Clin. Endocr. 3, 105-112.

McNeilly, A. S., Evans, G. E. \& ChaRd, T. (1973) Observations on prolactin levels during the menstrual cycle. In Human Prolactin, J. L. Pasteels and C. Robyn (Eds.), pp. 231-232. Excerpta Medica, Amsterdam.

Manlimos, F. S., Maroulis, G. B. \& ABraham, G. E. (1975) Radioimmunoassay of plasma 11-DOC. Analyt. Lett. 8,931-938.

Mattsson, B. \& von Schoultz, B. (1974) A comparison between lithium, placebo and a diuretic in premenstrual tension. Acta psychiat. scand. Suppl. 255, 75-84.

Mrchelakis, A. M., YoshidA, H. \& Dormois, J. C. (1975) Plasma renin activity and plasma aldosteronel during the normal menstrual cycle. Am.J. Obstet. Gynec. 123, 724-726.

Moos, R. H. (1969a) Typology of menstrual cycle symptoms. Am. J. Obstet. Gynec. 103, 390-402.

Moos, R. H. (1969b) Menstrual Distress Questionnaire. Preliminary Manual. Univ. Social Ecology Lab. Stanford, Calif.

Redmond, D. E., Murphy, D. L., Baulu, J., Ziegler, M. G. \& Lake, C. R. (1975) Menstrual cycle and ovarian hormone effects on plasma and platelet monoamine oxidase (MAO) and plasma dopamine-beta. hydroxylase (DBH) activities in the rhesus monkey. Psychosom. Med. 37, 417-428.

ReES, L. (1953) Psychosomatic aspects of the premenstrual tension syndrome. Br. J. Psychiat. 99, 62-73.

REICH, M. (1962) The variations in urinary aldosterone levels of normal females during the menstrual cycle. Australas. Ann. Med. 11, 41-49. 
Robyn, C., Delvoye, P., Nokin, J., Vekemans, M., Badawi, M., Perez-Lopez, F. R. \& L'Hermite, M. (1973) Prolactin and human reproduction. In Human Prolactin, J. L. Pasteels and C. Robyn (Eds.), pp. 167-188. Excerpta Medica, Amsterdam.

Rolland, R., Schellekens, L. A. \& Lequin, R. M. (1974) Successful treatment of galactorrhoea and amenorrhoea and subsequent restoration of ovarian function by a new ergot alkaloid 2 brom-a-ergocryptine. Clin. Endocr. 3, 155-165.

Rolland, R., Lequin, R. M., Schellekens, L. A. \& DeJong, F. H. (1975a) The role of prolactin in the restoration of ovarian functions during the early post-partum period in the human female. I. A study during physiological lactation. Clin. Endocr. 4, 15-25.

Rolland, R., DeJong, F. H., Schellekens, L. A. \& Lequin, R. M. (1975b) The role of prolactin in the restoration of ovarian function during the early post-partum period in the human female. II. A study during inhibition of lactation by bromergocryptine. Clin. Endocr. 4, 27-38.

Rose, D. P. (1969) Oral contraceptives and depression. Lancet ii, 321.

Rose, R. M. (1972) The psychological effects of androgens and estrogens: a review. In Psychiatric Complications of Medical Drugs, R. L. Shader (Ed.), pp. 251-293. Raven Press, New York.

Rubin, R. T., Poland, R. E. \& Tower, B. B. (1976) Prolactin related testosterone secretion in normal adult man. J. clin. Endocr. Metab. 42, 112-116.

Rubin, R. T., Gouin, P. R., Lubin, A., Poland, R. E. \& Pirke, K. M. (1975) Nocturnal increase of plasma testosterone in men: relation to gonadotropins and prolactin. J. clin. Endocr. Metab. 40, 1027-1033.

Schwartz, U. D. \& Abraham, G. E. (1975) Corticosterone and aldosterone levels during the menstrual cycle. Obstet. Gynec. 45, 339-342.

Seppala, M., Hirvonen, E., Ranta, T., Virkkunen, P. \& Leppaluoto, J. (1975) Raised serum prolactin levels in amenorrhoea. Br. med. J. ii, 305-306.

Singer, K., Cheng, R. \& Schou, M. (1974) A controlled evaluation of lithium in the premenstrual tension syndrome. Br. J. Psychiat. 124, 50-51.

Sletten, I. W. \& Gershon, S. (1966) The premenstrual syndrome: a discussion of its pathophysiology and treatment with lithium ion. Compreh. Psychiat. 7, 197-206.

Smith, S. L. (1975) Mood and the menstrual cycle. In Topics in Psychoendocrinology, E. J. Sachar (Ed.), pp. 19-58. Raven Press, New York.

Stokes, J. \& Mendels, J. (1972) Pyridoxine and premenstrual tension. Lancet i, 1177-1178.

Sundsfjord, J. A. \& AAKvaAG, A. (1970) Plasma angiotensin II and aldosterone excretion during the menstrual cycle. Acta endocr. 64, 452-458.

Sutherland, H. \& Stewart, I. (1965) A critical analysis of the premenstrual syndrome. Lancet i, 11801183.

Tonks, C. M. (1975) Premenstrual tension. In Contemporary Psychiatry, Br. J. Psychiat. Spec. Publ. No. 9, pp. 399-408.

TupIN, J. P. (1972) Lithium use in nonmanic depressive conditions. Compreh. Psychiat. 13, 209-214.

Varga, L., Lutterbeck, P. M., Pryor, J. S., Wenner, R. \& ERB, H. (1972) Suppression of puerperal lactation with an ergot alkaloid: a double-blind study. Br. med.J. ii, 743-744.

WETZEL, R. D. \& MCClure, J. N., JR. (1972) Suicide and the menstrual cycle: a review. Compreh. Psychiat. 13, 369-374.

Wetzel, J. N., Reich, T., McClure, J. N. Jr. \& Wald, J. (1975) Premenstrual affective syndrome and affective disorder. Br. J. Psychiat. 127, 219-221.

Williams, E. Y. \& WeEkes, L. R. (1952) Premenstrual tension associated with psychotic episodes. J. nerv. ment. Dis. 116, 321-329.

Winston, F. (1969) Oral contraceptives and depression. Lancet i, 1209.

Winston, F. (1973) Oral contraceptives, pyridoxine and depression. Am. J. Psychiat. 130, 1217-1221. 